\title{
El Espacio Público en Zonas de Conservación Patrimonial de Latinoamérica y el Caribe
}

\section{The Public Space in Heritage Conservation Zones of Latin America and the Caribbean}

\author{
DOI: 10.17981/mod.arq.cuc.26.1.2021.04
}

Artículo. Fecha de Recepción: 21/07/2020. Fecha de Aceptación: 12/11/2020.

\author{
Jair Díaz Barbosa \\ Universidad Autónoma del Caribe. Barranquilla (Colombia) \\ jair.diaz37@uac.edu.co
}

Aida Palmett Padilla

Universidad Autónoma del Caribe. Barranquilla (Colombia)

aida.palmett@uac.edu.co

Miguel Mayorga Cárdenas

Universidad Politécnica de Cataluña. Cataluña (España)

miguel.mayorga@upc.edu

\section{Agueda García Carrillo (iD}

Universidad Politécnica de Cataluña. Cataluña (España)

agueda.garcia@upc.edu

Para citar este artículo:

Díaz, J., Palmett, A., Mayorga, M. y García, A. (2021). El Espacio Público en Zonas de Conservación Patrimonial de Latinoamérica y El Caribe. MODULO ARQUITECTURA CUC, 26, pp. 83-112, 2021. DOI: http://doi.org/10.17981/mod.arq.cuc.26.1.2021.04

\section{Resumen}

El estudio presenta un análisis de la evolución de las dinámicas sociales reflejadas en el espacio público correspondiente a las zonas de conservación patrimonial de Latinoamérica y el Caribe. Inicialmente se describen las actividades necesarias y complementarias desarrolladas en el espacio público y su funcionalidad. Realizando una investigación descriptiva con fuentes secundarias de información, se identifican todas las zonas de conservación patrimonial, y se eligen cuatro centros históricos por su configuración urbana, comportamiento a través de la historia, similitud temporal después de la colonia en América y presentar un área de extensión entre 200 y 650 ha. Analizando los diferentes planes de desarrollo de estas zonas, y adoptando una metodología del marco lógico se logran resultados con escaso material de apoyo para los profesionales que generan ciudad, siendo necesario la implementación y utilización de tecnologías emergentes, para desarrollar una trazabilidad a todos y cada uno de los elementos que componen el espacio público; y así tener a disposición la información adecuada, y en tiempo real, para la toma de decisiones, logrando una verdadera sostenibilidad.

Palabras clave: Sostenibilidad; planificación; espacio público y nuevas metodologías

\section{Abstract}

The study presents an analysis of the evolution of the social dynamics reflected in the public space corresponding to heritage conservation areas in Latin America and the Caribbean. Initially, the necessary and complementary activities developed in the public space and their functionality are described. Carrying out a descriptive research with secondary sources of information, all the heritage conservation areas are identified, and four historical centers are chosen for their urban configuration, behavior through history, temporal similarity after the colony in America and present an area of extension between 200 and 650 ha. Analyzing the different development plans of these areas, and adopting a logical framework methodology, results are achieved with little support material for professionals who generate cities, being necessary the implementation and use of emerging technologies, to develop a traceability to each and every one of the elements that make up the public space; and thus have available adequate information, and in real time, for decision making, achieving true sustainability. Keywords: Sustainability; planning; public space and new methodologies

(c) The author; licensee Universidad de la Costa - CUC. 


\section{INTRODUCCIÓN}

A través de la historia el espacio público ha representado el entorno físico de las urbes donde se refleja las dinámicas sociales, estas dinámicas se representan en el día a día cuando los peatones caminan por las aceras, algunos grupos conversan, transeúntes que se saludan, los ancianos sentados en las bancas y de más actividades que se presentan en el exterior.

Para Gehl (2009), describe las condiciones físicas que debe tener el espacio urbano para desarrollar las actividades exteriores, categorizadas en las actividades necesarias $y$ obligatorias realizadas por los peatones, como son: las caminatas para el estudiante poder trasladarse a la institución académica, o la ama de casa que realiza el recorrido al ir al supermercado a efectuar las debidas compras; habitualmente estas actividades se realizan por medio de la acción de caminar. Las actividades opcionales corresponden a las relacionadas con la recreación y resultan agradables para la comunidad, dependiendo de las condiciones físicas externas y siendo favorables solo si el tiempo y las características del lugar invitan a la gente a detenerse, sentarse, comer, jugar, etcétera. Y las actividades sociales, siendo también denominadas como resultantes, al depender de la presencia de otras personas para que haya interacción en los espacios públicos peatonales; producidas de manera espontánea en los espacios privados exteriores, como terrazas, edificios públicos, jardines etcétera, y como consecuencia de las actividades necesarias y opcionales implicadas indirectamente (Figura 1).

Los espacios públicos de todo tipo, desde las pequeñas calles residenciales hasta la plaza de la ciudad se usan siempre y cuando tengan la calidad requerida, cabe resaltar que la vida cotidiana, las actuaciones de la sociedad y los espacios en los cuales ocurren estas dinámicas sociales diarias, deben concentrar la atención y esfuerzos multi e interdisciplinares. Los requisitos para estos espacios urbanos se considera que son las condiciones deseables para las actividades exteriores necesarias, actividades opcionales y recreativas y actividades sociales, para permanecer en las ciudades y las zonas residenciales con confianza y moverse fácilmente, logrando disfrutar de los espacios, los edificios y la vida callejera, además de encontrarse y reunirse con otras personas de manera organizada o informalmente, siendo fundamental para la visión de ciudades sostenibles (Gehl \& Svarre, 2013).

Es importante señalar que la función principal del espacio público es proporcionar el escenario para generar las dinámicas sociales, actividades cotidianas como la circulación peatonal o las estancias cortas, etc. Son actividades sencillas sociales que permiten desarrollar una vida comunitaria como lo desean los residentes del lugar. El aspecto funcional es el que determina estos espacios comunitarios interiores y exteriores; sin dejar a un lado el aspecto visual 
Modul. Arquit. CUC 26, 83-112, 2021

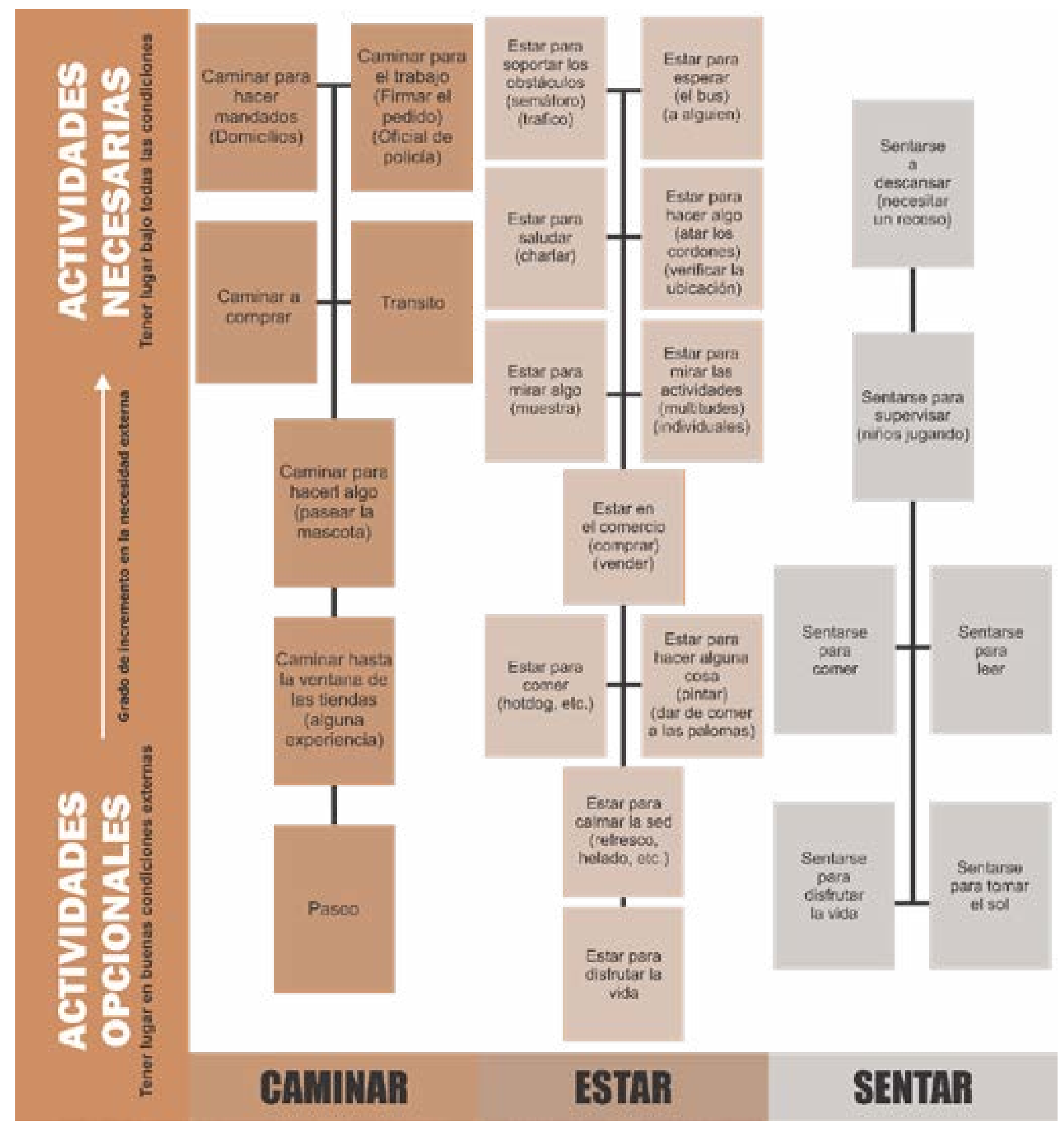

Figura 1. Actividades necesarias, opcionales y sociales del Espacio Urbano.

Fuente: Gehl \& Svarre (2013). 
en la estructura fisica, emplazando las viviendas alrededor de las plazas o calles de grupos residenciales (Matan \& Newman, 2016).

La mayor expresión de aspecto visual lo representan las edificaciones por determinar un valor cultural y patrimonial inmerso, debido a la arquitectura o tendencia reflejada en sus fachadas e interiores. El espacio público de las zonas de conservación patrimonial siempre se encuentra sometidas a imposiciones, por ser consideradas como recurso cultural de gran importancia para la humanidad, considerando estos espacios urbanos como hábitats de interés comunitario de diversas actividades necesarias, opcionales y sociales, pero también por ser considerados conectores que propician diversos flujos de movilidad (Aroüelles, Gómez y Argüello, 2014).

Zonas de conservación patrimonial en Latinoamérica y El Caribe

La Organización de las Naciones Unidas para la Educación, la Ciencia y la Cultura (UNESCO, 2016) describe que el patrimonio se encuentra definido en los espacios públicos de calidad o zonas marcadas por el paso del tiempo, y se

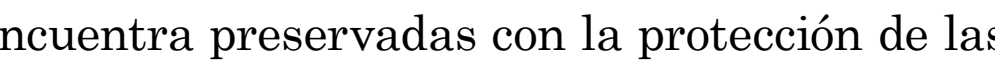
identidades urbanas. El desarrollo de la comunidad va ligado a la importancia de preservar as zonas historicas de las ciudades, donde el patrimonio urbano desempeña el papel fundamental para reflejar las identidades de las ciudades, siendo este espacio una plataforma de desarrollo social y económico.

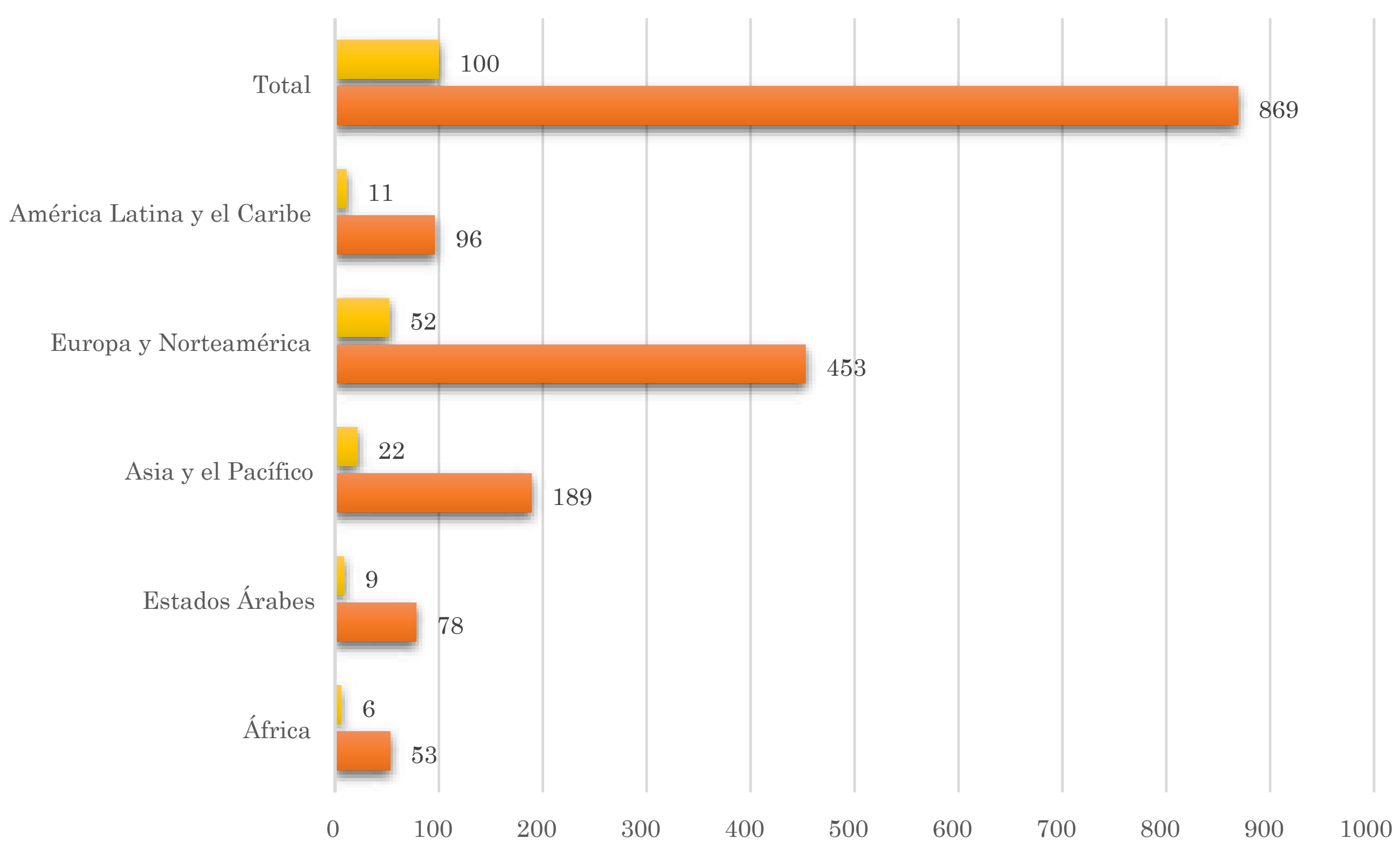

\begin{tabular}{|l|c|c|c|c|c|c|}
\cline { 2 - 7 } \multicolumn{1}{c|}{} & África & $\begin{array}{c}\text { Estados } \\
\text { Árabes }\end{array}$ & $\begin{array}{c}\text { Asia y } \\
\text { el Paćfico }\end{array}$ & $\begin{array}{c}\text { Europa y } \\
\text { Norteamérica }\end{array}$ & $\begin{array}{c}\text { América Latina } \\
\text { y el Caribe }\end{array}$ & Total \\
\hline $\mathbf{\square}$ Porcentaje & 6 & 9 & 22 & 52 & 11 & 100 \\
\hline $\mathbf{\square}$ Cultural & 53 & 78 & 189 & 453 & 96 & 869 \\
\hline
\end{tabular}

Las zonas de conservación patrimonial se definen como sectores del territorio de una población que cuentan con una fisionomía, rasgos y caracteristicas distintivas las cuales se determinan como singular por su particularidad. Estas zonas pueden corresponder a una centralidad urbana o barrios tradicionales de cada ciudad (República de Colombia. Ministerio de Cultura, Mincultura, 2011). En la actualidad, la UNESCO (1982) ha identificado y relacionado a 869 zonas de conservación patrimonial a nivel mundial (Figura 2).

Estas zonas para América Latina y el Caribe representan el 11\% con 96 zonas de conservación patrimonial y un total de 43 centros históricos, con más de 10 millones de habitantes, distribuidas en Antigua y Barbuda, Argentina, Barbados, Bolivia, Brasil, Chile, Colombia, Costa Rica, Cuba República Dominicana, Ecuador, El Salvador, Guatemala Haití, Honduras, México Sanamá, Paraguay, Perú, Saint Kitt and Nevis, Suriname, Uruguay y Venezuela. teveruela. humanidad se ubican a lo largo de toda Latinoárica y el Caribe, desde el Centro histórico de Cón (Uruguay) ye Barrio históico del Puerto cindo (Uruay) y el Chile) (Figura 3)

Figura 2. Lista de Patrimonio Mundial para la UNESCO. Fuente: UNESCO, CC BY-SA 3.0 OIG.
Disponible en https://whc.unesco.org/en/list/stat 


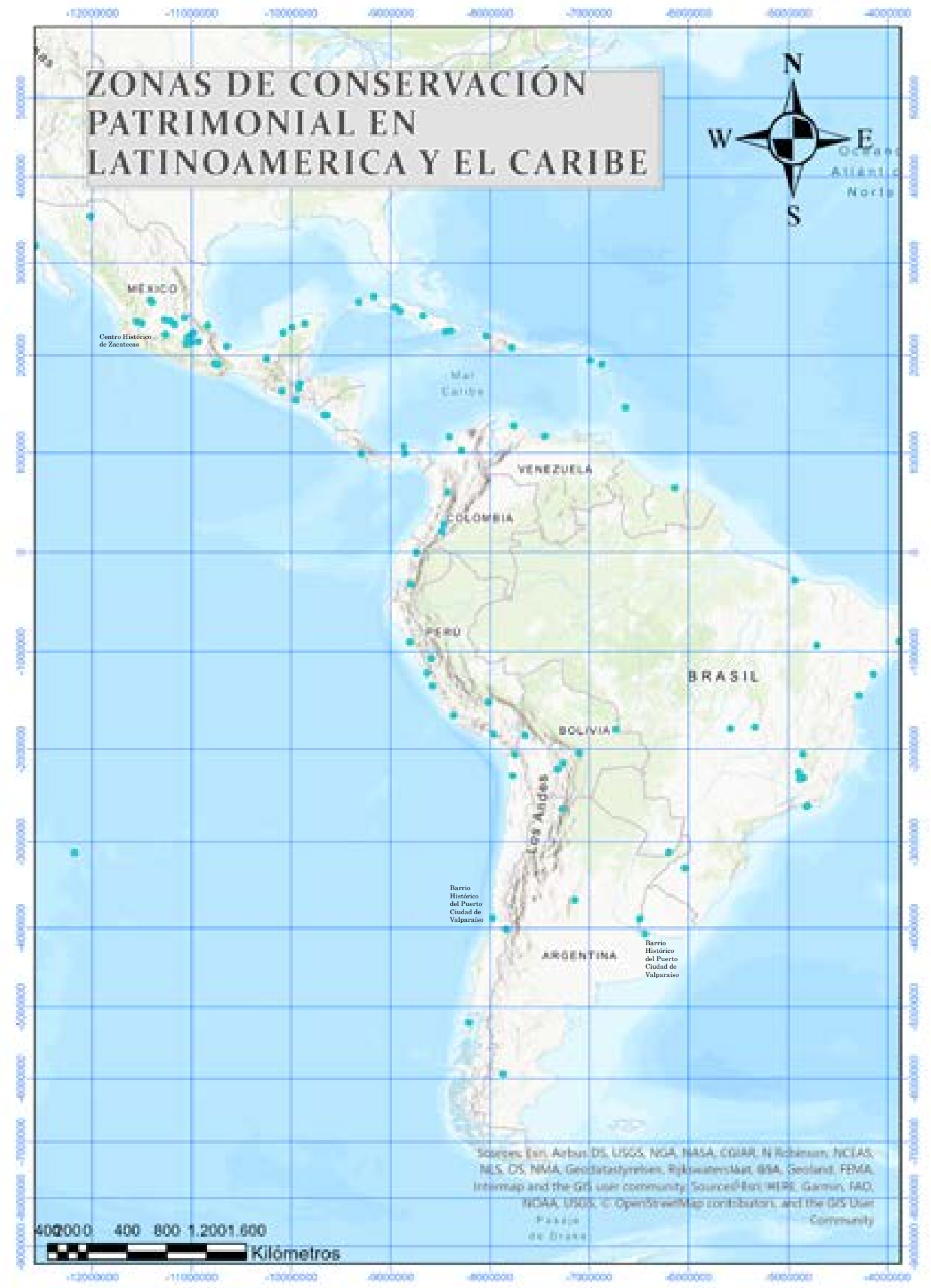

Figura 3. Patrimonio Cultural en Latinoamérica y el Caribe. 
El Centro histórico de Zacatecas (México). Zacatecas se fundó en 1546 después y alcanzó el apoge dl su pro Gibrided en los y alcanzó el apogeo de su prosperidad en los
siglos XVI y XVII (Panico y Garibay, 2010). Construido en las empinadas laderas de un estrecho valle, la ciudad tiene unas vistas impresionantes y hay muchos edificios animpresionantes y hay muchos edificios anñones, 2017). La catedral, construida entre 1730 y 1760 , domina el centro de la ciudad. Destaca por su diseño armonioso y la profusión barroca de sus fachadas, donde se encuentran elementos decorativos europeos e indígenas (Estado de Zacatecas. Secretaria de Turismo, 2019).

El Barrio histórico de la ciudad de Colonia del Sacramento (Uruguay). Sacramento es fundada por los portugueses en 1680 en el Río de la Plata; la ciudad fue de importancia estrategica para resistir a los españoles. Después de sor disputado durante un siglo, sus fundadores finalmente lo perdieron. El paisaje urbano bien conservado ilustra la exitosa fusión de los portugués, español y poscolonial.

El Barrio histórico del Puerto ciudad de Valparaíso (Chile). La ciudad colonial de Valparaiso presenta un excelente ejemplo de desarrollo urbano y arquitectónico de finales del siglo XIX en América Latina. En su entorno natural similar a un anfiteatro, la ciudad se caracteriza por un tejido ur-

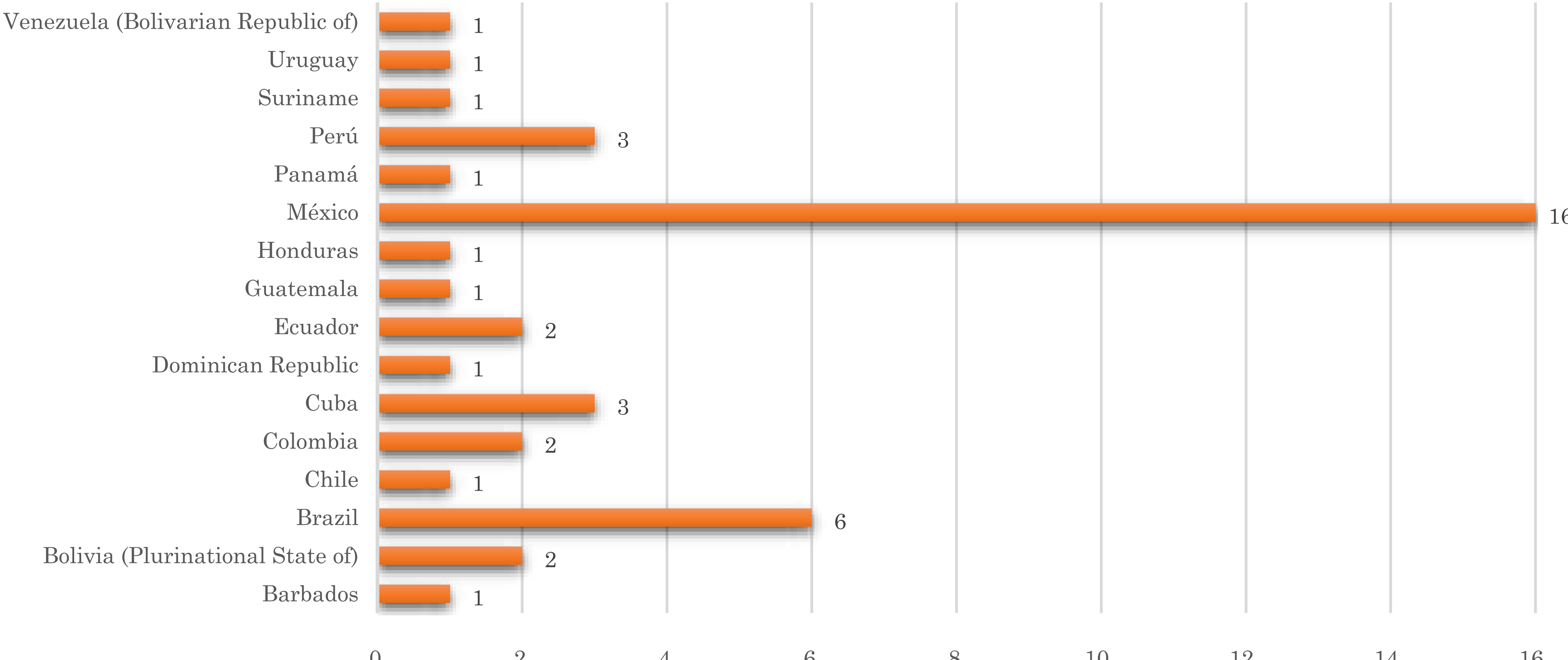

Figura 4. Zonas de Conservación Patrimonial de Latinoamérica y el Caribe. Fuente: Elaboración propia. 
están salpicadas de una gran variedad de agujas de iglesia. Contrasta con el diseño geométrico utiliz. Con la llanura. La ciudad ha conservado bien sus interesantes infraesnumerosos 'ascensores' en las empinados laderas (Estrada, 2000).

Uno de los criterios a considerar que pertenece a zona de conservación patrimonial de la humanidad es la singularidad en su estructura urbana, la cual se encuentra caracterizada por su espacio público como lo son las calles, las plazas, equipamientos y demás, siendo estos espacios un transcendental protagonismo al urbanismo mundial. Por estas razones, poseen un semblante de protección especial definido por cada administración pública, resaltando la importancia de su función original que asumieron o tuvieron en el momento de su fundación las zonas de conservación patrimonial (Organización de las Naciones Unidas, ONU, 2000)

Ya identificados todas las zonas de conservación patrimonial de la humanidad para América Latina y el Caribe, se pretende realizar un análisis de las zonas más representativas en cuanto a extensión en hectáreas y lograr identificar las metodologías implementadas con éxito en el espacio público para mejorar las condiciones con enfoque de sostenibilidad (Tabla 1).
1.

Extensión de las zonas de Conservación de Latinoamérica y el Caribe

\begin{tabular}{|c|c|c|c|c|c|}
\hline País & Nombre & Área hectáreas & País & Nombre & Área hectáreas \\
\hline Barbados & El Centro histórico de Bridgetown y su guarnición militar & 187 & & Centro histórico de la ciudad de México y Xochimilco & 0 \\
\hline Bolivia & Ciudad de Potosí & 0 & & Ciudad prehispánica de Chichén-Itzá & 0 \\
\hline Bolivia & Ciudad histórica de Sucre & 0 & & Zona de monumentos históricos de Querétaro & 0 \\
\hline \multirow{6}{*}{ Brasil } & Ciudad histórica de Ouro Preto & 0 & & Villa protectora de San Miguel & 46,95 \\
\hline & Centro histórico de San Salvador de Bahía & 0 & & Zona de monumentos históricos de Tlacotalpan & 75 \\
\hline & Centro histórico de la ciudad de Diamantina & 28,5 & & Ciudad universitaria central & 176,5 \\
\hline & Centro histórico de la ciudad de Goiás & 40,3 & & Ciudad histórica fortificada de Campeche & 181 \\
\hline & Centro histórico de São Luís & 66,65 & & Centro histórico de Zacatecas & 207,72 \\
\hline & Centro histórico de la ciudad de Olinda & 120 & México & Ciudad prehispánica de Teotihuacan & 250 \\
\hline Chile & Barrio histórico del Puerto Ciudad de Valparaíso & 23,2 & & Centro histórico de Oaxaca & 375 \\
\hline \multirow{3}{*}{ Colombia } & Puerto, Fortalezas Cartagena & 0 & & Centro histórico de Morelia & 390 \\
\hline & Centro histórico de Santa Cruz de Mompox & 0 & & Centro histórico de Puebla & 690 \\
\hline & Centro histórico de Camagüey & 54 & & Centro histórico de México y Xochimilco & 707,65 \\
\hline \multirow[t]{2}{*}{ Cuba } & Centro histórico Urbano de Cienfuegos & 70 & & Ciudad prehispánica & 1772 \\
\hline & La Habana Vieja y su Sistema de Fortificación & 238,7 & & Ciudad prehispánica de Uxmal & 2059,8 \\
\hline República Dominicana & Ciudad colonial de Santo Domingo & 106 & & Ciudad histórica de Guanajuato & 2167,5 \\
\hline \multirow{2}{*}{ Ecuador } & Centro histórico de Santa Ana de los Ríos de Cuenca & 224,14 & & Camino Real de Tierra Adentro & 3101,91 \\
\hline & Ciudad de Quito & 320 & Panamá & Distrito histórico de Panamá & 57,4 \\
\hline Guatemala & Antigua Guatemala & 0 & & Ciudad de Cuzco & 142,48 \\
\hline Honduras & Sitio Maya de Copán & 15,095 & Perú & Centro histórico de la ciudad de Arequipa & 166,52 \\
\hline Uruguay & Barrio histórico de la ciudad de Colonia del Sacramento & 16 & & Centro histórico de Lima & 259,36 \\
\hline Venezuela & Ciudad universitaria de Caracas & 164,203 & Surinam & Casco histórico de Paramaribo & 30 \\
\hline
\end{tabular}

Fuente: Elaboración propia a partir de https://whc.unesco.org/ 


\section{Metodología}

Para nuestra investigación, se realizó el análisis comparativo con fuentes secundarias de investigación, teniendo en cuenta su comportamiento urbano a través de la historia después de la colonia española, también sus configuraciones espaciales y dinámicas económicas relacionadas con la expansión descontrolada por cada uno de estos centro históricos de Latinoamérica y el Caribe. Las zonas de conservación patrimonial corresponden a Cuba con la Habana Vieja con una extensión de 238,7 hectáreas; Ecuador con la ciudad de Quito con 320 hectáreas; México con el Centro histórico de Puebla con 690 hectáreas y Perú con el Centro histórico de Lima con 259,36 hectáreas.

\section{DESARROLLO}

\section{La Habana Vieja - Cuba}

La Habana Vieja - Cuba, denominada por las autoridades, navegantes y viajeros como "Llave del Nuevo Mundo", tiene sus inicios para el siglo XVI con la construcción de la Villa de San Cristóbal en la Habana, donde se desarrolló la estructura urbana y arquitectónica que hasta el día de hoy representa por sus valores históricos. El desarrollo urbano policéntrico que estaba conformada por plazas, en las cuales funcionaban para diferentes actividades fundamentales, siendo el punto de encuentro para los habitantes y visitantes (Castillo y Ríos, 2013). La Habana durante su periodo colonial se expandió con una trama compacta influenciada por la ascendencia hispánica, con una estructura irregular de formas diversas en las mazanas y distintos tamaños, con calles irregulares y angostas, y donde la arquitectura se entrelazaba con las paredes comunes o medianeras de cada edificación (Zardoya, 2014).

Una de las características relevantes de la arquitectura habitacional de La Habana es su patio y traspatio, siendo este espacio ocupado para el cultivo rural asociado a ofrecer a los habitantes un espacio con condiciones de vivienda de calidad de vida generosa, esta estructura es representativa de las ciudades jardín (Gavira, 1975). Estas edificaciones con inspiración ecléctica, tuvieron su cambio en las primeras décadas del siglo XX con la llegada de las nuevas dinámicas económicas influenciadas por el capital financiero norteamericano (Valdivieso y González, 2015), logrando cambiar la estructura habitacional en una área con una nueva imagen más simple, menos adornos, generalizando la simetría, reemplazando las columnas y los dinteles por arcos, los frontones circulares son modificados por triangulares y aparecen de nuevo las balaustradas, representando una arquitectura neoclásica reflejada en la nueva edificación con alturas más elevadas en el centro histórico, denominándolo en aquel entonces como el "Wall Street Habanero" (Menéndez, 2007). El movimiento moderno tiene protagonismo para la década de los 40 y 50 con el incremento de la población de clase media y alta en las zonas urbanas, consecuencia de un desarrollo acelerado reflejado en la construcción de nuevas vías, puentes, túneles, permitiendo una mejor movilidad y conexión de la ciudad (Rey, 2012). 
Establecida la revolución en 1959, la administración de turno enfoco provincias del interior del pais, desarrollando diferentes estudios demográficos, sociales, redes técnicas y de protección al medio ambiente, ocasionando un descuido en la Habana Vieja, que conllevo a un deterioro en las edificaciones (Figura 5). Como resultado, se genera una congestión y las ciudadelas demuestran hacinamiento con condiciones de inhabitabilidad por las diferentes actividades, obligando a la sociedad de estrato alto a reubicarse sobre las periferias donde obtendrían mejores condiciones de higiene y confort habitacional (González, 2009).

Para 1982 el centro histórico de la Habana es designado por la UNESCO (1982) como patrimonio de la humanidad, definiéndolo como habitado, representado por diversas actividades habitado, represeniado por diversas actividades rales. Restan también que algun yon se encontrabon en detrimento debido a sus años de construcion y los usos ino te su funcion; lon unes ina han ocurido diferentes demoliciones pero aún conserva su homogeneidad ambiental. Describen que en el plan general de la ciudad debe existir un plan particular para la revitalización y restauración de las construcciones de más valor cultural, enfocados únicamente en las edificaciones y demostrando ausencia de interés sobre el espacio público de la zona de conservación patrimonial tes, ICOMOS, 1982).

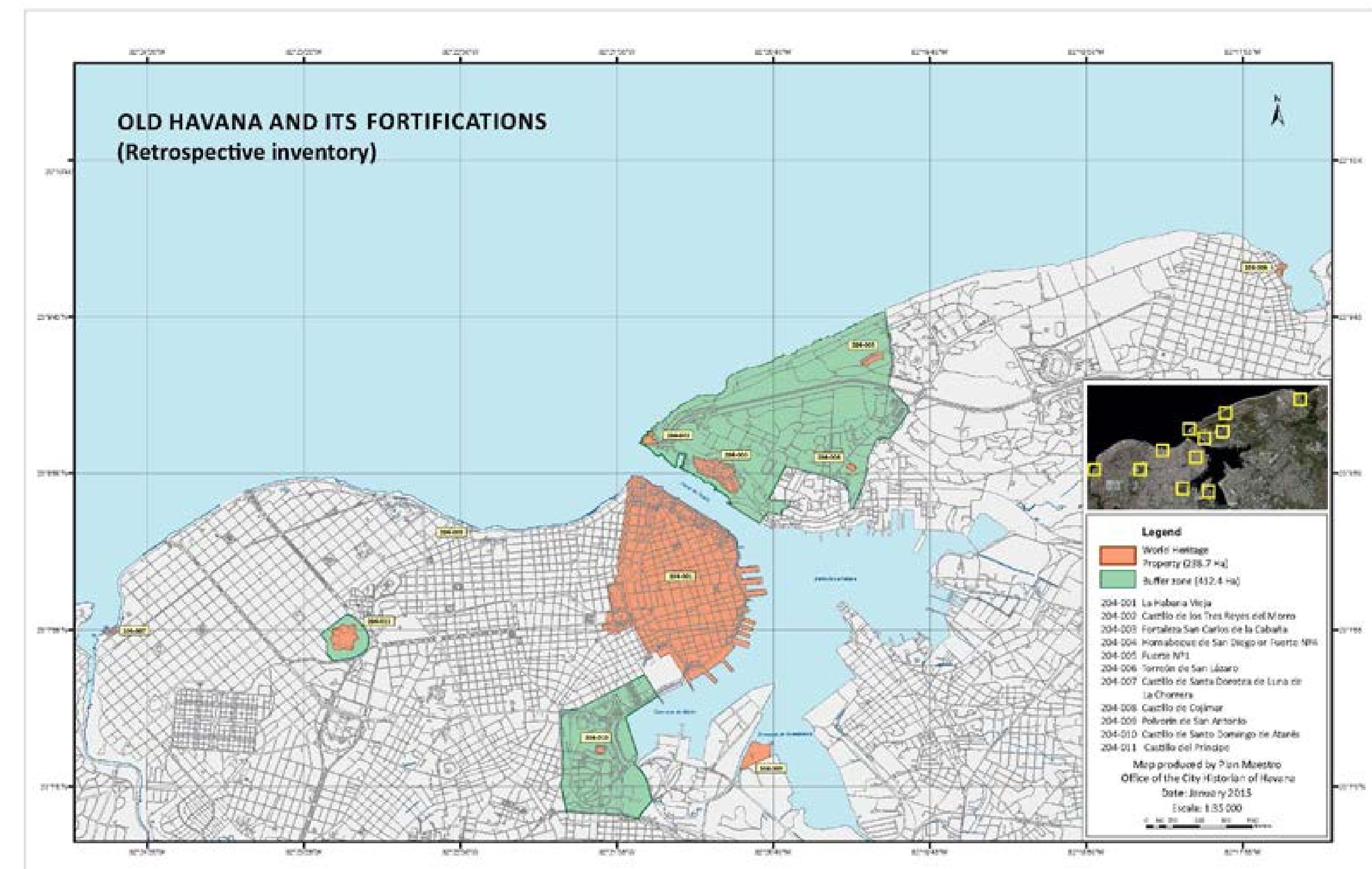

Figura 5. La Habana Vieja y su Sistema de Fortificación Fuente: UNESCO, CC BY.SA 3.0 OIG. Disponible en https://I
whe.unesco.orglen/list/204/multiple=1\&unique_number=225
La Oficina del Historiador de la Ciudad de el Plan Especial de Desarrollo Integral (PEDI) hasta el 2030, siendo un documento de gestion territorial que define los lineamientos y pautas del ordenamiento y desarrollo urbano del patrimonio cultural del Centro Histórico de La Habana con un enfoque de sostenibilidad. Aunque este plan ha logrado desarrollo social, cultural y educacional, continúan las barreras económicas de inversión, debido a que prevalece la economía dual con las transacciones internacionales para la compra de materiales necesarios para el proceso de restauración y rehabilitar el fondo construido (Mestre y Castillo, 2017) El actual PEDI, formulado por la Oficina del Historiador de la Ciudad de la Habana (2016), define una serie de estrategias enfocadas en el desarrollo sostenible contemplando la Dimensión Social, teniendo en cuenta al ser humano como sujeto fundamental de la obra rehabilitadora, logrando una equidad, prosperidad y la mejor solución a los conflictos sociales; Dimensión Económi $c a$, con el objetivo de fomentar el desarrollo de la economía local con criterios de descentralización y basada en los principios de economía social y solidaria con un suso racional de los recursos; Dimensión Ambiental, comprendiendo la cultura ambientalista y resiliente, preservando el contexto, asegurando el bienestar de los individuos y brindándoles seguridad social; y por último la Dimensión Cultural, fortificando la identidad local para lograr una consolidación del patrimonio tangible e intangible, apoyando la diversidad cultural e impulsando las industrias culturales y. economías creativas. 


\section{La Ciudad de Quito - Ecuador}

La Ciudad de Quito - Ecuador, denominada en la época colonial como "Quito y sus cinco leguas", con su plaza principal llamada "San Francisco", en la cual convergían las redes viales locales, siendo estas redes el elemento de articulación para su desarrollo económico y social, ya que transitaba las fuerzas armadas, los mercaderes y las familias para sus actividades necesarias, convirtiendo a Quito en la centralidad política y administrativa de la región (Aguilar et al., 1992).

Entre los años de 1570 y 1580, se experimenta un crecimiento poblacional debido al comercio y mercado que en esta zona se concentraba, logrando una urbanización significativa de 300 viviendas, para 1650 se había registrado un total de 2500 viviendas con 3500 habitantes, además el paisaje urbano estaba constituido por huertas, jardines y animales, logrando un ambiente campesino, adoptando el paisaje natural en su hábitat. Por consecuencia era necesario mejorar los servicios públicos en este caso el agua, y más cuando llegaban a esta zona los ejércitos; se dice que se generaron quebradas artificiales por los Incas para albergar a toda la comunidad, demostrando ese crecimiento acelerado en pocas décadas (Enríquez, 1938).

Según Deler, Gomez y Portais (1983), para el siglo XIX ya contaba con 40.000 habitantes, donde seguía resaltándose las actividades económicas dependientes de la producción rural, tejidos de algodón, de lana y seda, los artículos manufacturados correspondía a los sombreros de paja, alpargatas, cestos, alfombras, bordados, hilos, ponchos, sandalias, jabón, cigarros, aguardiente, pólvora, confites, pinturas en lienzo y cerámica; su espacio público no se encontraba completamente consolidado, con la característica de representar un asentamiento disperso o semirural.

Para comienzos del siglo XX, la plaza central representaba el núcleo administrativo donde funcionaba toda la administración de la región, sobre esta zona se ubicaban los españoles, un poco más alejados del centro, estaban ubicados los criollos, y por ultimo y sobre la periferia se ubicaban las clases populares (Gómez, 1995). Para mediados del siglo, Quito contaba con una población de 211 mil habitantes (registro del primer censo de población). La respuesta para este crecimiento social durante más de dos décadas, fue la construcción de los servicios públicos, destruyendo las calles empedradas que representaban una de las identidades culturales de esta zona de conservación patrimonial, para construir la red de agua potable y consecuentemente la pavimentación de las calles (Miño, 2018).

La zona de conservación patrimonial de Quito fue reconocida por la UNESCO (1982), como uno de los dos primeros centros históricos de Patrimonio Cultural de la Humanidad para el año 1978, con 70.000 habitantes y 300.000 personas como población flotante. Representando en su momento el poder colonial, donde se ve reflejado las tendencias de estilos y épocas en la arquitectura de las iglesias, los conventos, y el palacio presidencial, 
la alcaldía y algunos ministerios y entidades del estado (Godard, 1986).

Después de la actividad telúrica de 1987, varias de sus edificaciones comenzaron a deteriorarse, para 1992, la administración de turno planifico la recuperación de esta zona de conservación patrimonial, formulando el plan maestro del casco histórico. En el plan estaba incluido la peatonalización del centro, recuperando los espacios públicos, como plazas correspondientes a las edificaciones representativas (Sahady y Gallardo, 2004).

En el Plan Parcial para el Desarrollo Integral del Centro Histórico de Quito - Propuesta Estratégica del Distrito Metropolitano de Quito (Instituto Metropolitano de Patrimonio - IMP, 2019), se determina el diagnóstico del espacio público, y define que para el 2010, el espacio público, y define que para el 2010, el espacio
público disponible del centro histórico de Quito correspondía al $4,7 \%$ de la superficie total, determinando una índice da superficie total, determinando una indice de $4,24 \mathrm{~m}^{2}$ por habitante. (Organización Panamericana de la Salud, OPS, 2016), se define el espcio público mín. 2016), se demo para cada cuadrados disponibs. Demostrando muy por debajo el espacio

El plan también determina que el $75 \%$ de los residentes expresa realizar sus actividades en los espacios públicos recreativos de la ciudad y solo el $41 \%$ lo realiza en los espacios disponiDebido a las condiciones de baja calidad de los

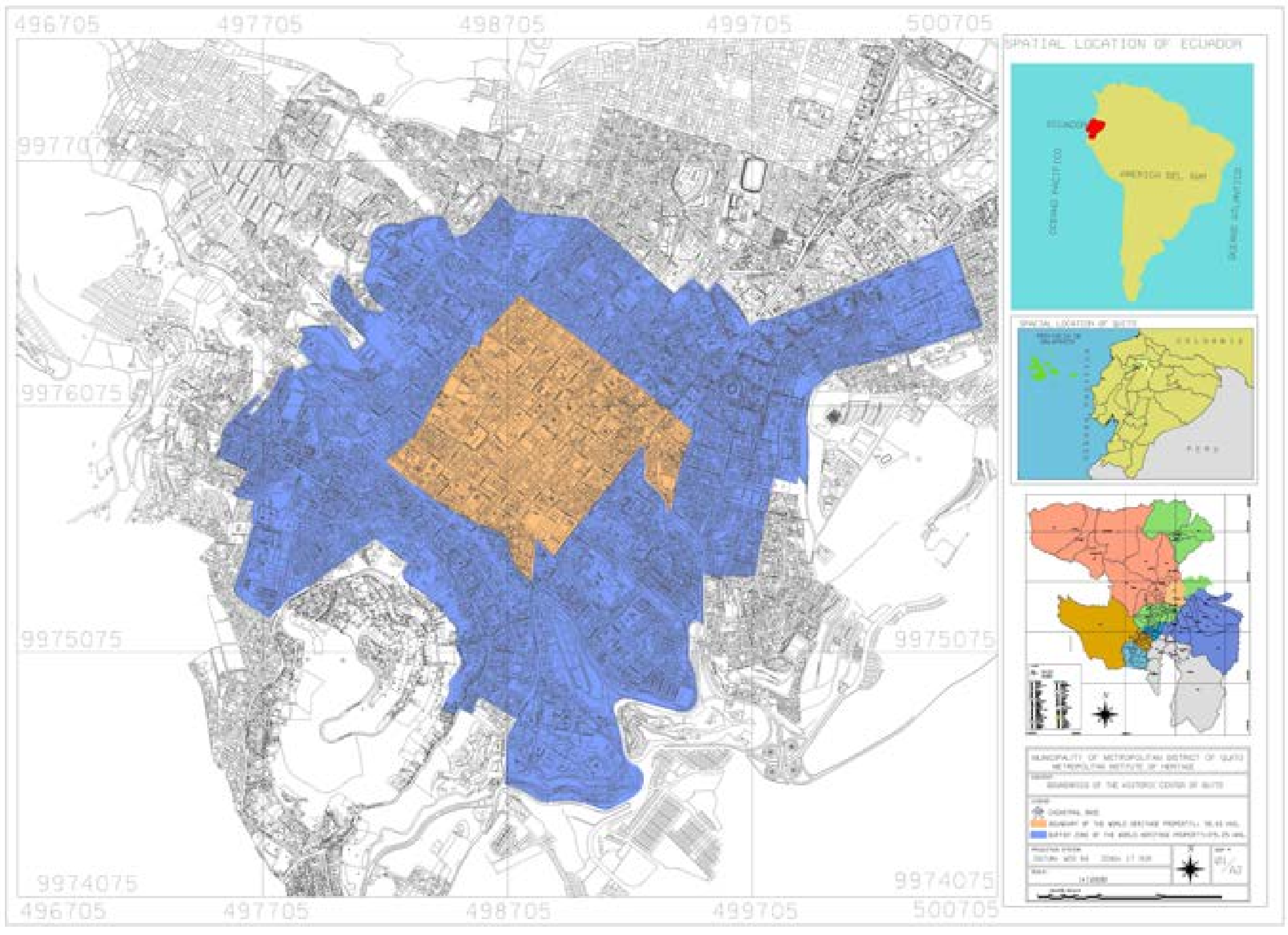

Figura 6. Centro Histórico de Quito y Su Área de Influencia Fuente: UNESCO, CC BY-SA 3.0 OIG. Disponible en https://
whc.unesco.org/en/list/2/multiple=1\&unique_number $=5$ equipamientos y la percepción de inseguridad de la población, ya que en esta zona se manejan los microtráficos de sustancias alucinógenas y el trabajo sexual (Instituto de la Ciudad de Quito, 2016). Otra de las problemáticas es la apropiación del espacio público para ferias y expresiones culturales sin ninguna autorización de la administración pública para estos eventos. El comercio informal está identificado con aproximadamente 1.682 comerciantes, obstruyendo la libre movilidad de los peatones y afectando la calidad de espacio público (Agencia Metropolitano de Control, 2020).

En el Plan Parcial para el Desarrollo Integral del Centro Histórico de Quito (IMP, 2019), se espera que con el apoyo de la comunidad en general se logre dar cumplimiento a los lineamientos establecidos por Hábitat III (ONU, 2016), y pretende un desarrollo sostenible con los objetivos de la Agenda 2030 de la ONU (2015).

Formulando como objetivo general: "Mejorar Mejorar las condiciones de habitabilidad, garantizando cepcionales, como un mecanismo de desarollo para todos los actores que conviven en el Centro Histórico de Quito" (IMP, 2019), el primer objetivo especifico teritorio, territorio, phi for maran espacio público que garantice espacios seguros

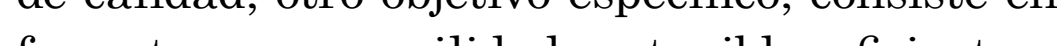
fomentar una movilidad sostenible, eficiente y y reduzca las acesible, que priorice al peatón y reduzca las emisiones contaminantes. 


\section{El Centro Histórico de Puebla-México}

El Centro Histórico de Puebla - México, ciudad denominada inicialmente como "Ciudad de los Ángeles”. Para 1531 inicia su creación partiendo de la segunda audiencia de la Nueva España. Para el emplazamiento de esta nueva ciudad se aprovechó la disposición de las tierras fértiles para los diferentes cultivos y la ganadería, por su posición geográfica para la defensa, y por la accesibilidad a diferentes caminos que interconectaban el comercio entre las ciudades de México, Veracruz y la región de Oaxaca. Para este año fueron los primeros trazados de la ciudad, con la construcción de la iglesia y 50 viviendas alrededor de ella, lo que actualmente conforma el centro histórico (Lomelí, 2011).

Una de las primeras obras urbanas, fue la construcción de la red de suministro de agua a la población, siendo este elemento fundamental en el desarrollo de Puebla. El trazado de la ciudad correspondía en similitud al de la antigua roma, tomado como punto central la plaza principal, careciendo de mobiliario urbano, y alrededor con una configuración compacta y firme, con manzanas de forma rectangular para favorecer la evacuación del agua hacia el río (Montero, 2010).

Para la primera mitad del siglo XIX, Puebla contaba con 305 manzanas urbanas, conservando su estructura original de 4.26 kilómetros de extensión física, ya que se habían realizado pocas modificaciones durante el periodo colonial
(Vélez, 2007). Debido a su progreso económico, las clases altas lograron sustituir sus edificaciones por mansiones de estilos románticos con materiales de costos elevados, la mayoría importados desde Europa, cambiando la estructura de la ciudad a una tendencia de arquitectura francesa. Para inicios del siglo XX, después de la revolución mexicana, el desarrollo urbano de la ciudad de Puebla fue estático. Pero la década de los 40 a los 60, debido a la revolución industrial fue impulsado este desarrollo con la construcción de nuevos proyectos en las periferias, con un diseño ortogonal, apareciendo los nuevos asentamientos no planificados y sin control (Salamanca, 2005).

En 1987 el centro histórico de Puebla (México) fue reconocido por la UNESCO como patrimonio mundial de la humanidad, con 391 manzanas y 2.619 edificios catalogados. Este título fue obtenido gracias a la historia que la ciudad de Puebla representa, con lugares de distinción que guardan memorias trascendentales en diversos monumentos históricos, religiosos, civiles, escultóricos y conmemorativos (García, 1991).

Con 488 años de historia, esta zona de conservación patrimonial es uno de los centros históricos más grandes que tiene Latinoamérica y el Caribe, con una arquitectura única que representa su cultura y tradición en las iglesias, fuentes, plazas, conventos, patios y fachadas, brindándole a la ciudad una característica única, convirtiéndolo en un centro urbano trascendental (Gil, 2009). 


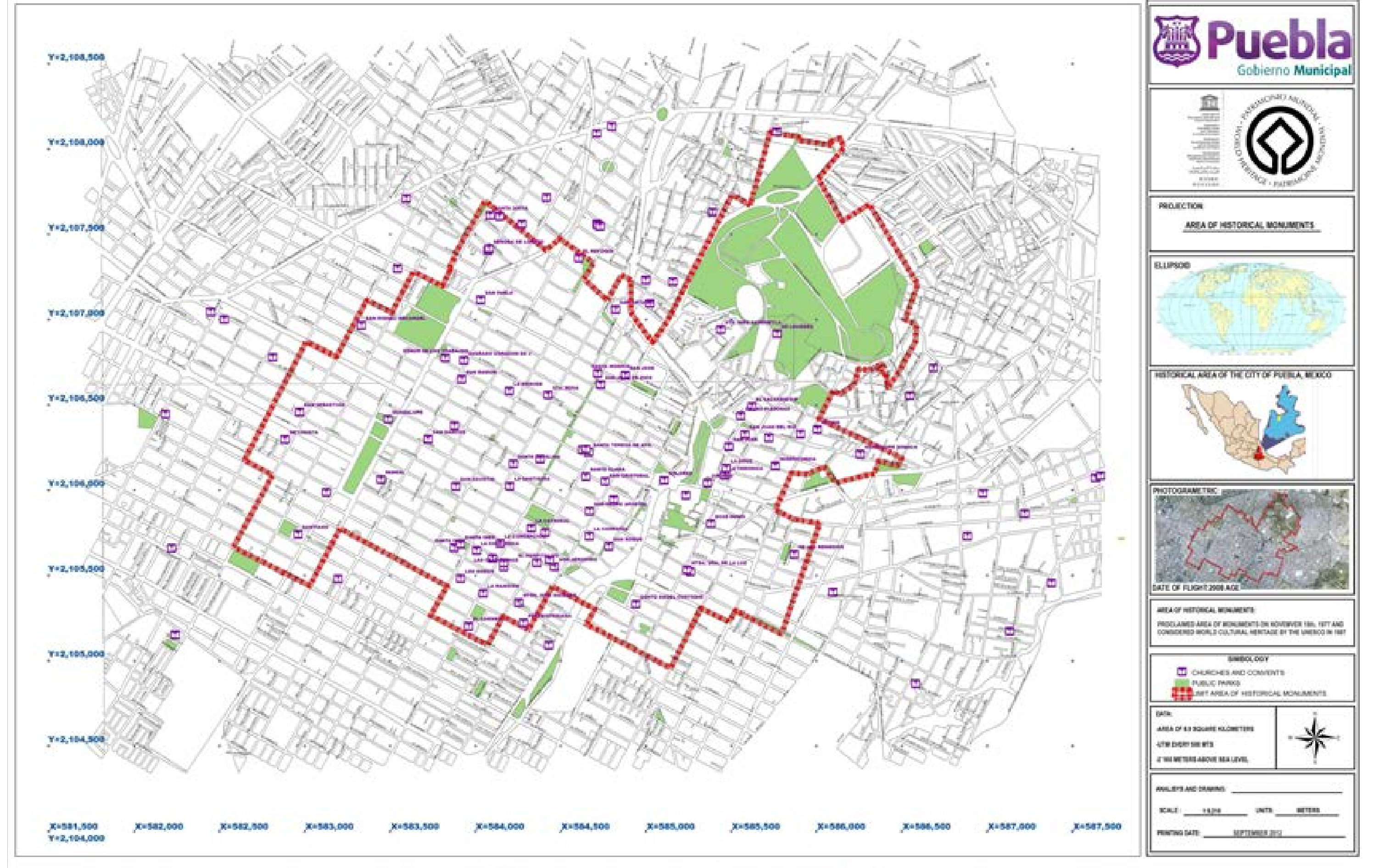

Figura 7. Área limítrofe del Centro histórico de Puebla, México.

Fuente: UNESCO, CC BY-SA 3.0 OIG. Disponible en https://whc.unesco.org//en/list/116/multiple=1\&unique_number=479
Para Cruz, Pérez, Torralba y Bonilla (2017) centro historico de Puebla es la falta de cultura por parte de sus residentes y la falta de conocimiento que representa una zona de conservación patrimonial de la humanidad, generando poco compromiso en la conservación por parte de la ciudadanía, sumado a esto la falta de recursos por parte de las diferentes administraciones, dificulta su mantenimiento y conservación, causando una amenaza de desaparición en las futuras generaciones (Figura 7).

El Programa Parcial de Desarrollo Urbano Sustentable del Centro Histórico del Municipio de Puebla, formulado por él Gobierno del Estado de Puebla (2015), define en su diagnóstico 87 espacios públicos con un total de 956.615,04 m² caracterizando los elementos que componen la traza de las diferentes calles, zócalos, plazuelas, jardines, paseos, camellones, rotondas y canct ja falta de mas cench acios públicos; perdida de las áreas verdes en

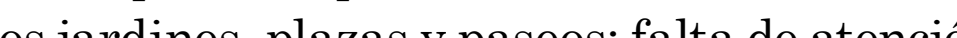

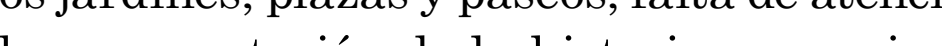
de te con de los trones falta de oxigencion de las déc to ló falta ce oxigenacion de las localizach y estad fisco del a de señán y estado fisico del arbolado, falta de senalética y mobiliario adecuado, invasión que no cumplen con la normativa establecida, ocasionando contaminación visual incoherente con el contexto patrimonial que repes existencia de cableado aéreo de las diferentes empresas públicas, deteriorando la imagen urbana y representando riesgos potenciales; el mobiliario urbano de distintas épocas en deterioro, resultado del vandalismo o del escaso mantenimiento con el paso del tiempo; y la degradación de las banquetas, el representado hundimiento por asentamiento diferencial, demostrando deterioro por el constante mantenimiento en las obras de infraestructura, deterioro de las guarniciones y rampas en algunas esquinas, limitando la movilidad peatonal de la zona.

El Centro Histórico de Lima - Perú

El Centro Histórico de Lima - Perú, Lima del quechua Limac que significa "el Dios que habla". Como diferentes ciudades de Latinoamérica y el Caribe, Lima no podía ser la excepción de ubicar su plaza central y alrededor las unidades habitacionales, cuando los españoles construyen la capital del virreinato del Perú, imponiendo sobre la trama existente (Figura 8), representada con 117 manzanas y un total de 214 hectáreas, apropiándose con violencia cultural, se trataba de una refundación simbólica, dejando en un segundo plano e importancia la sociedad nativa y marcando los inicios de un orden urbano renacentista, resaltando su centro colonial (Ludena, 2002). 


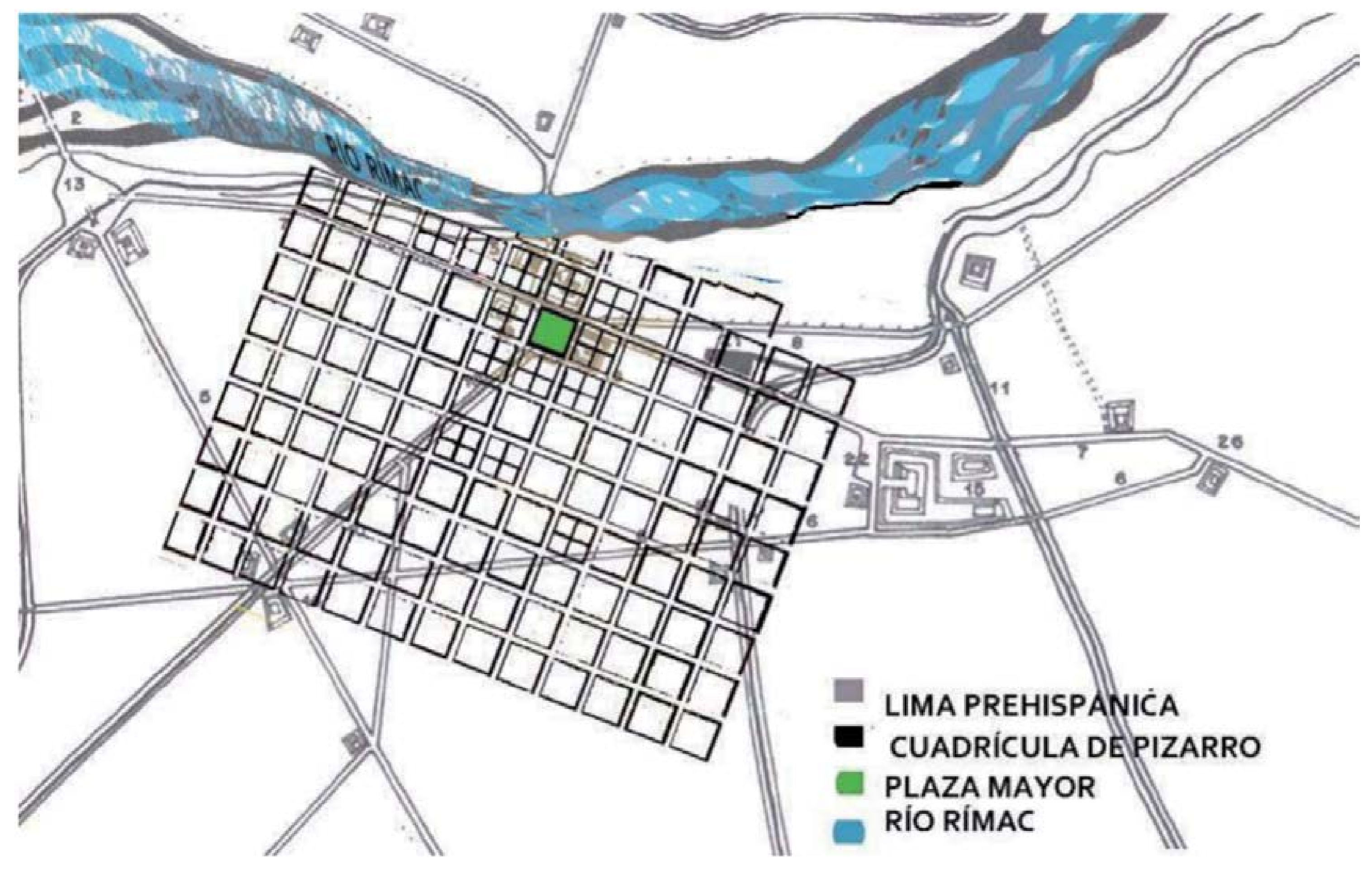

Figura 8. Plano de Lima con el primer trazado urbano sobre la trama prehispánica. Fuente: Hamann (2011)
El modelo clásico de ciudad hispanoamérica, representaba diferentes características, como lo eran el trazado geométricos, destacando las parcelas destinadas a solares urbanos y con asignación a cada habitante, con calles anchas y derechas, emplazadas con orientación del Sudeste al Noroeste, permitiendo que en todo el día una acera tuviera sombra, aprovechando la dirección de los vientos alisios provenientes del sur logrando una circulación pel aire, la plaza central teńa la característica visul qua central tenía la caracteríslo lejos el mar (Las, 1927). Para el ing XVII, Lima

a tuvo una expansión fragmentada acelerada, con un aumento de 41 manzanas (Alexander, 1927). Para esta misma época se logró la construcción de la muralla, con 11.800 metros lineales, cinco a seis metros de alto, cinco de ancho desde su base y cinco puertas, eliminando la trama geométrica que representaba el modelo de ciudad hispanoamericana (Günther, 1983). Para mediados del XVIII, la ciudad habría tenido modificaciones, resultado de los diferentes movimientos sísmicos; cabe resaltar que esta zona representa uno de los lugares con más sísmico del planeta. En el año de 1746 ocurrió el movimiento telúrico más fuerte, acompanado de maremoto, perdiendo un $10 \%$ de la ciudad, obligando a la reconstrucción de la ciudad, con materiales prehispánicos (PérezMallaína, 2005)
A principios del siglo XIX, el crecimiento de la ciudad representaba 211 manzanas, siendo necesario la creación de nuevos espacios de mayor circulación y salubridad, demostrando

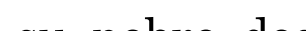
del siglo la situación ecón. Para cambio, con

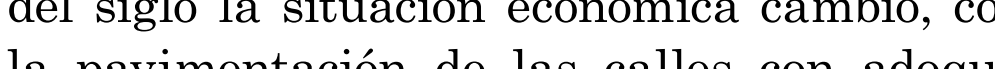
nes, implación de ilu calcos con adorilámparas de gas, se recmpozó las tubín

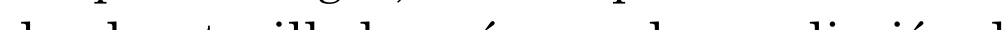
de alcantarillado, a como la las tuberion de vís (Vargas, 1966).

Para finales del siglo XIX y principios de PX; se proyectó de expansión urbana de la Ciudad, Cinda y la constución de nuevos escenarios, destruyendo la muralla que limitaba la ciudad de Lima (Bromley y Barbagelata, 1945), con las diferentes construcciones y expansiones. Lima se convierte en una ciudad moderna y además se desdibuja los límite de la traza colonial; cabe resaltar que en e centro de la ciudad permanecieron los estratos bajos "tugurios" y para las periferias del lado sur se trasladaron la clase acomodada (Harth-Terré, 1935). Para la mitad del siglo pasado, los cambios económicos y sociopolít cos, deterioraron la cludad con una image urbana caduca y obsoleta del centro histórico de Lima (Seppänen, 2003). 


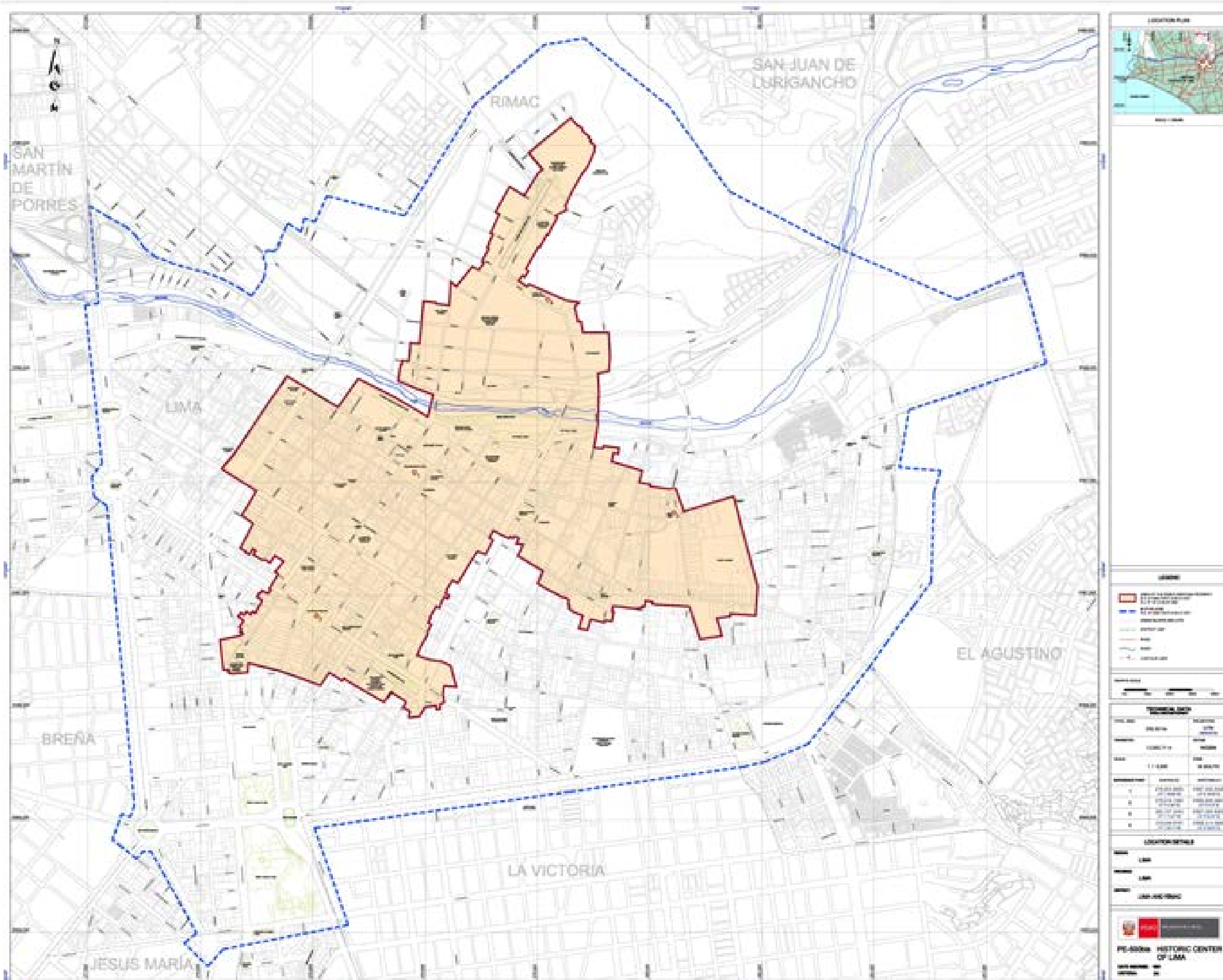

Figura 9. Centro Histórico de Lima - Perú.

Fuente: UNESCO, CC BY-SA 3.0 OIG. Disponible en https://whc.unesco.org//en/list/500/multiple=1\&unique_number=583
En el año 1987, fue formulado el Plan del Centro de Lima (Comisión Especial del Cercado de Lima, 1987), estableciendo unos neamientos enfocados en un desarrollo sostenible, con el propósito de evitar el deterioro del centro histórico. Los capítulos correspondientes a este plan fueron: Capítulo 1) La realidad Urbanística de base; Capitulo 2) El medio ambiente y su crisis; Capítulo 3) El sistema circulatorio; Capitulo 4) Vivir en el cercado; Capitulo 5) Interpretación y propuestas ante el proceso urbano de la dinámica actual; y Capitulo 6) La propuesta: programas y proyectos del plan. Siendo este documento la ruta a seguir para los próximos años y fuera la normativa que permitiera que el 12 de diciembre 1991, esta zona fuera reconocida a nivel mundial como centro histórico patrimonial de la humanidad por la UNESCO (1992), basado en los criterios de la convención y que basado en los criterios de la convención y que porta un excelente testimonio de desarrollo les. Con una extensión de 259,36 hectáreas y un total de 766,7 hectareas en su área de

Para la Municipalidad Metropolitana de Lima (2014) en su Plan Maestro del Centro Historico de Lima al 2025, describe la proinapropiado espacio público como un estado nentedia por la economía informal, con los 3 mil cos anbulantes que representan unos enco tica es notable mostrando en ciertas áreas unos decibeles de 80 , donde la OMS define un confort acústico en un rango de máximo 50 decibeles, el transporte obsoleto que se moviliza por esta zona, genera una contaminación al aire con material particulado y gases de combustión alterando las condiciones favorables del aire, otro foco de contaminación de gases al medio ambiente son los restaurantes, la red de suministro de energía eléctrica no se encuentra en condiciones adecuadas para brindar un servicio seguro, se estima que habrá perdidas de suministro por colapso de los postes y hurto de cableados y equipos, y el espacio público peatonal no se encuentra en la mejores condiciones de generar una movilidad del peatón, mostrando una discontinuidad en su configuración y además generando exclusión con las personas de movilidad reducida (Figura 9).

\section{Resultados}

Para la Vieja Habana - Cuba, el ordenamiento territorial y urbano, está enfocado a la promoción de la heterogeneidad funcional contemplando las intensidades asociadas a la estructura urbana y los valores patrimoniales arquitectónicos, e incorporando la funcinalidad contempónea para accesibilidad universal, con garantizar su namizadora del espacio público, la movilidad, y respetando las cociciones a la inistidad, de la política ambiental para su desarrollo.

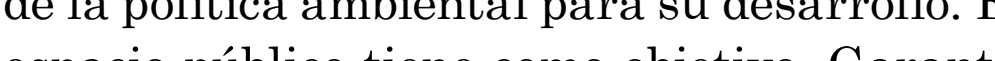


zar el pleno disfrute del espacio, desglosado en cinco objetivos específicos, 1) Recuperar la calidad y excelencia del espacio público; 2) fortalecer la ordenación, funcionalidad y apropiación ciudadana; 3) Fomentar el uso intensivo; 4) Promover la accesibilidad universal; y 5) Garantizar seguridad ciudadana.

En el Plan Parcial para el Desarrollo Integral del Centro Histórico de Quito elaborado por IMP (2019), se espera que con el apoyo de la comunidad en general se logre dar cumplimiento a los lineamientos establecidos por Hábitat III y pretende un desarrollo sostenible con los objetivos de la Agenda 2030 de las Naciones Unidas. Formulando como objetivo general: Mejorar las condiciones de habitabilidad, garantizando la conservación de sus Valores Universales Excepcionales, como un mecanismo de desarrollo para todos los actores que conviven en el Centro Histórico de Quito, el primer objetivo específico responde a la situación y del territorio, para fomentar una cultura de uso de espacio público que garantice espacios seguros de calidad; otro objetivo específico, consiste en fomentar una movilidad sostenible, eficiente y universalmente accesible, que priorice al peatón y reduzca las emisiones contaminantes.

Las estrategias del Programa Parcial de Desarrollo Urbano Sustentable del Centro Histórico del Municipio de Puebla definido por (Gobierno del Estado de Puebla, 2015), están enfocadas a fortalecer el centro urbano metropolitano y su área de influencia, respondiendo al ordenamiento y regulación del territorio con una visión sustentable, fomentando la habitabilidad urbana, preservando su identidad y renovando su viabilidad económica, social y cultural. La estrategia territorial urbana, aborda los aspectos de Estructura Urbana pretendiendo concretar una estructura física que respete las características históricas y culturales, brindándole un impulso a la vivienda reforzando vocación comercial, de servicios, turística y cultural, con objetivos específicos en la Traza urbana, polígonos de actuación, polos concentradores de actividades, ejes estructurales, reparto entre actividad y residencia; Conectividad, Accesibilidad y Movilidad Urbana con enfoque en el transporte público, gestión del automóvil su viabilidad, movilidad no motorizada, accesibilidad y movilidad para personas con discapacidad, viabilidad y dispositivos para el control del tránsito; Equipamiento y Servicios con un subsistema asistencial social, sistema de recreación y deporte, creación de nuevos espacios públicos, conformación de centros y parques, lineamientos de arquitectura de paisaje para el conjunto, lineamientos de los espacios urbanos seguros, actuación en arbolado existente y equipamiento cultural; Usos y Destinos de Suelo con una zonificación actualizada; Densidades; actualizando la vivienda en edificios artísticos e históricos; y Ocupación e Intensidad en las Construcciones con un coeficiente de ocupación y utilización del suelo y numero de niveles permitidos. 
Las estrategias del Plan Maestro del Centro Histórico de la Municipalidad Metropolitana de Lima (2014) definen que debe ser un instrumento de gestión que orienta los usos del suelo, las acciones, intervenciones, el control, los programas y proyectos y las inversiones públicas y privadas en su ámbito territorial, con la finalidad de conservar, recuperar y realzar sus valores formales, históricos y culturales, en concordancia con su valor intrínseco y su significado para la Nación. Donde uno de sus objetivos consiste en propiciar la concertación de los agentes públicos y privados y de los actores sociales, económicos y culturales, asumiendo compromisos compartidos que impulsen el desarrollo local y la solución de los problemas críticos; Preservar y mejorar los espacios públicos para garantizar la seguridad ciudadana en el ámbito de su jurisdicción.

\section{Discusión}

Las zonas de conservación patrimonial de Latinoamérica y el caribe, demuestran unas problemáticas similares, que durante la historia fueron acontecimientos surgidos en paralelo, como los son la expansión física urbana hacia las periferias, fracturando su centro histórico. El proceso culpable de estas situaciones corresponde a la planificación con sus instrumentos administrativos metodológicos desarrollados, demostrando falta de comunicación y coherencia entre las instituciones públicas y las demandas de la sociedad, generando inconformidad entre la calidad de vida en los espacios públicos y los intereses políticos y económicos de la administración de turno, lo que conlleva a una degradación del patrimonio edificado y su pérdida de habitabilidad.

\section{Conclusiones}

Analizando la evolución hasta llegar a la actualidad con los diferentes planes maestros o parciales se puede concluir que las metodologías utilizadas a lo largo de la historia representan el mismo proceso convencional y tradicional, que consiste en realizar un levantamiento para obtener un inventario de los elementos del espacio público de estas zonas de conservación patrimonial, para luego analizar las condiciones en que se encuentran, seguido del análisis se evalúa las fortalezas y debilidades que representan, para así, formular un plan de acción que sea coherente con el desarrollo de la zona estudiada, generando objetivos para cada elemento que constituye el espacio urbano.

La planificación de estas zonas, carecen de información producida por la metodología implementada, ya que en algunos casos solo se tiene en cuenta los datos históricos para luego realizar una proyección distribuida, siendo necesario obtener todos los datos en tiempo real, para los profesionales que construyen y se encargan de un desarrollo urbano, para 
lograr este propósito se hace necesario la implementación y utilización de las diferentes herramientas tecnológicas y digitales que se encuentran disponibles en la actualidad, para generar procesos articulados del espacio público con las dinámicas sociales producidas, resaltando la identidad cultural singular de cada una de estas zonas de conservación patrimonial.

\section{REFERENCIAS}

Aguilar, P., Bustos, G., Goetschel, A., Kingman, E., Luna, M., Ospina, P., Pérez, J., Ramón, G., Soasti, G. y Terán, R. (1992). Enfoques y Estudios: Quito a Través de la Historia. Quito: Dirección de Planificación del Municipio de Quito. Junta de Andalucía.

Alexander, A. (1927). Los Problemas Urbanos de Lima y su Futuro. Lima: La Prensa.

Argüelles, B., Gómez, J. y Argüello, T. (2014). Gestión y Percepción del Espacio Público Patrimonial. Caso de Estudio: Centro Histórico de San Cristóbal de las Casas, Chiapas, México. En, Paredes (Coord.) Relaciones entre la Teoría y las Concreciones en la conservación del patrimonio cultural edificado (pp. 297-308). Yucatán: Universidad Autónoma de Yucatán.

Bromley, J. y Barbagelata, J. (1945). Evolución Urbana de la Ciudad de Lima. Lima: Consejo Provincial de Lima.
Castillo, M. y Ríos, M. (2013). La Habana Vieja, Un Presente Audaz. RCUB, Revistes Cientifiques de la Universitat de Barcelona, (25), 37-56. Disponible en https://revistes.ub.edu/index.php/waterfront/article/ view/18872

Cruz, J. A., Pérez, A., Torralba, A. y Bonilla, B. (2017). Puebla, México "Ciudad Patrimonio de la Humanidad" Percepción Ciudadana. International Journal of Scientific Management and Tourism, 3(2), 273-298. Disponible en http://www.ijosmt.com/index.php/ ijosmt/article/view/233

Deler, J. P., Gómez, N. y Portais, M. (1983). El manejo del Espacio en el Ecuador. Quito: Geografia Historica.

Distrito Metropolitano de Quito. Agencia Metropolitano de Control. (2020). Agencia Metropolitano de Control. [Online]. Disponible en http://agenciadecontrol.quito.gob.ec/

Distrito Metropolitano de Quito. IMP. (2019). Plan Parcial para el Desarrollo Integral del Centro Histórico de Quito - Propuesta Estratégica. Quito: IMP. Recuperado de https://n9.cl/jois

Enríquez, E. (1938). Quito a través de los Siglos. Quito: Imprenta Municipal. Disponible en http://repositorio.casadelacultura.gob.ec/ handle/34000/875

Estado de Zacatecas. Secretaria de Turismo. (2019). Zacatecas, Catalogo Turístico. [Onli$n e]$. Zacatecas: Zacatecastravel. Disponible en https://www.zacatecas.gob.mx/ 
Estrada, B. (2000). Valparaíso: sociedad y economía en el siglo XIX. [Serie Monografías históricas, No. 12]. Viña del Mar: Universidad Católica de Valparaiso.

García, E. (1991). Monumentos de la Ciudad de Puebla. Puebla: Centro de Estudios Históricos de Puebla.

Gavira, C. (1975). Transformación Urbana en Cuba: La Habana. Revista Española de la Opinión Pública, (42), 181-184. https://doi. org/10.2307/40182445

Gehl, J. (2009). La Humanización del Espacio Urbano. Barcelona: Reverté.

Gehl, J. \& Svarre, J. G. (2013). How to Study Public Life. Washington: Islandpress.

Gómez, N. G. (1995). Pasado y Presente de la Ciudad de Quito. Quito: EDIGUIAS C.

Gil, R. (2009). Patrimonio Natural - Cultura del Estado de Puebla. Puebla: Grafica Total.

Gobierno del Estado de Puebla. Secretaría General de Gobierno. (2015). Programa Parcial de Desarrollo Urbano Sustentable del Centro Histórico del Municipio de Puebla. Periódico Oficial del Estado de Puebla: Número 17, Quinta Sección, Tomo CDLXXXVI.

Godard, H. R. (1986). Análisis Comparado de los Centros y de los Lugares de Centralidad de Quito y Guayaquil. Cultura: Revista del Banco Central del Ecuador, 8(24c), 889895. Disponible en http://www.documentation.ird.fr/hor/fdi:26538
González, D. (2009). Medio Siglo de Vivienda Social en Cuba. Revista INVI, 24(67), 6992. Disponible en http://www.revistainvi. uchile.cl/index.php/INVI/article/view/466

Günther, J. (1983). Planos de Lima 1613 - 1983. Lima: Municipalidad de Lima Metropolitana.

Hamann, J. (2011). Monumentos Públicos en Espacios Urbanos de Lima 1919 - 1930. Barcelona: Universidad de Barcelona.

Harth-Terré, E. (1935). Lima Contemporánea. Lima en el IV centenario de su fundación. Lima: Minerva.

Instituto de la Ciudad de Quito. (2016). Encuesta Multipropósito en el Centro Histórico de Quito CHQ. [Online]. Disponible en http://sid.quito.gob.ec/SID.Front/Dashboard

ICOMOS. (1982). Lista de Patrimonio Mundial. Paris: ICOMOS. Disponible en https://www. icomos.org/en

Laos, C. (1927). Lima - La Ciudad de los Virreyes. Lima: Perú.

Lomelí, L. (2011). Puebla - Historia Breve. México D.F.: Fondo de la Cultura EconómicaFCE.

Ludena, W. (2002). Lima: Poder, Centro y Centralidad: del Centro Natico al Centro Neoliberal. Revista EURE, 28(83), 45-65. http://dx.doi.org/10.4067/S025071612002008300004 
Matan, A. \& Newman, P. (2016). People Cities: The Life and Legacy of Jan Gehl. Washington: Island Press.

Menéndez, M. (2007). La Casa Habanera: Tipología de la Arquitectura Doméstica en el Centro Histórico. La Habana: Editorial Boloña.

Mestre, M. y Castillo, A. (2017). Retos Urbanos y Medioambientales para una Mejor Gestión del Patrimonio Cultural en Cuatro Ciudades del Caribe: La Habana, San Juan Viejo, Santo Domingo y Cartagena de Indias. Arquitectura, Ciudad y Entorno, 11(33), 87-116. http://dx.doi.org/10.5821/ ace.11.33.4784

Miño, W. (2018). Ferrocarril y Modernización en Quito: Un Cambio Dramático entre 1905 y 1922. Quito: Casa Andina. Disponible en http://hdl.handle.net/10644/6539

Municipalidad Metropolitana de Lima. (2014). Plan Maestro del Centro Histórico de Lima al 2025. Lima: Prolima.

Municipalidad Metropolitana de Lima. Comisión Especial del Cercado de Lima. (1987). Plan del Centro de Lima. Lima: INVERMET.

ONU. (2016). La Agenda para el Desarrollo Sostenible. [Online]. Disponible en https:// habitat3.org/the-new-urban-agenda

ONU. (2015). Agenda 2030. [Online]. Disponible en https://www.un.org/ sustainabledevelopment/es/developmentagenda/
ONU. (2000). Instrumentos y Estrategias de Gestión Urbana para el Desarrollo Sustentable en América Latina y el Caribe (GUDS). Santiago: Comisión Económica para América Latina y el CaribeCEPAL.

Oficina del Historiador de la Ciudad de la Habana. (2016). PEDI. Plan Especial de Desarrollo Integral 2030 La Habana Vieja-Centro Histórico. La Habana: Editorial Boloña. Disponible en http://www. planmaestro.ohc.cu/index.php/instrumentos/pedi

OMS. OPS. (2016). Planificación Urbana, Salud y Sostenibilidad. Santiago de Chile: Organización Mundial de la Salud-OMS. Recuperado de https://www. paho.org/chi/index.php?option $=\mathrm{com}_{-}$ docman\&view $=$ dow nload\&alias $=195$ areas - verdes $-5 \&$ category_slug $=$ otras publicaciones\&Itemid $=1145$

Montero, C. (2010). Arquitectura y Urbanismo: de la Independencia a la Revolución: dos Momentos Claves en la Historia Urbana de la Ciudad de Puebla. México, D.F.: Educación y Cultura Asesoría y Promoción.

Panico, F. y Garibay, C. (2010). Mazapil, Zacatecas, Mexico: Un Ejemplo de Estructura Agroganadera Colonial (1568-1810). Fronteras de la Historia, 15(1), 61-84. Disponible en https://revistas.icanh.gov.co/index. php/fh/article/view/411 
Pérez-Mallaína, P. E. (2005). Las catástrofes naturales como instrumento de observación social: el caso del terremoto de Lima en 1746. Anuario de Estudios Americanos, 62(2), 4776. https://doi.org/10.3989/aeamer.2005.v62. i2. 49

Quiñones, G. (2017). La vida picaresca en Zacatecas, siglos XVI y XVII : juegos, pleitos y blasfemias. Nuevo mundo mundos nuevos, [Online], Debates. https://doi.org/10.4000/nuevomundo.71229

República de Colombia. MinCultura. (2011). Formulación e Implementación de Planes Especiales de Manejo y Protección de Bienes Inmuebles de Interés Cultural. Bogotá, D.C.: Dirección de Patrimonio. Disponible en https:// www.mincultura.gov.co/areas/patrimonio/planes-y-programas/Paginas/Planes-Especialesde-Manejo-y-Protecci\%C3\%B3n.aspx

Rey, G. (2012). Repensar La Habana: En Búsqueda de la Sustentabilidad Urbana. RIURB, Revista Iberoamericana de Urbanismo, (7), 43-67. Disponible en http://hdl.handle. net/2099/12536

Sahady, A. y Gallardo, F. (2004). Centros Históricos: El Auténtico ADN de las Ciudades. Revista INVI, 19(51), 9-30. Disponible en http://www.revistainvi.uchile.cl/index.php/ INVI/article/view/64/46

Salamanca, J. (2005). Puebla (México): Una Ciudad Histórica ante un Futuro Incierto. Scripta Nova, 9(194). Disponible en https:// revistes.ub.edu/index.php/ScriptaNova/article/view/958
Seppänen, M. (2003). Historia Local y Patrimonio Mundial. Ciudad Letrada, Arcaica Colonial y el Centro Histórico de Lima. Anuario Americanista Europeo, (1), 107-120.

UNESCO. (2016). Cultura: Futuro Urbano. [Informe]. Paris: UNESCO. Disponible en https://es.unesco.org/creativity/publication/ cultura-futuro-urbano

UNESCO. (1992). Historic Centre of Lima. [Online]. Obtenido de https://whc.unesco.org/ en/list/500/

UNESCO. (1982). Convention Concerning the Protection of the World Cultural and Natural Heritage. [CLT-82/CONF.015/8] Paris: UNESCO. Available: http://whc.unesco.org/ en/sessions/06COM

Valdivieso, E. y González, F. (octubre, 2015). Arquitectura ecléctica residencial en la ciudad de la Habana (municipios de Habana Vieja y Centro Habana) entre 1900 y 1930. Fuentes documentales. Actas IX Congreso Nacional de Historia de la Construcción (vol. 3, pp. 1715-1725). Universidad Politécnica de Madrid, Segovia, España. Recuperado de http://www.sedhc.es/biblioteca/ actas/166-Valdivieso.pdf

Vargas, R. (1966). Historia General del Perú. El Descubrimiento y la Conquista. Lima: Milla Batres.

Vélez, F. (2007). Planeación crecimiento urbano y cambio social en el centro histórico de la ciudad de Puebla. Puebla: Benemérita Universidad Autónoma de Puebla. 
Zardoya, M. V. (octubre, 2014). La Historia de la Habana Contada por sus Casas. Conferencia impartida en IV Convención de Arquitectura y Urbanismo (pp. 11-17). Universidad Tecnológica José Antonio Echeverría, La Habana, Cuba. Recuperado de http://www.ipf.gob.cu/ sites/default/files/revista/Maria\%20V\%20 Zardoya.pdf
Jair Díaz Barbosa es Ingeniero Industrial, doctorando en Sostenibilidad.

Aida Palmett Padilla es Arquitecta, doctorando en Sostenibilidad.

Miguel Mayorga Cárdenas es Arquitecto con doctorado en Gestión del Territorio. https://orcid. org/0000-0002-3389-3541

Agueda García Carrillo es Ingeniera Química y Licenciada en Ciencias Químicas. Doctora $(\mathrm{PhD})$ en Ingeniería de Sistemas Técnicos. https://orcid.org/0000-0003-0472-9491 